\title{
INFECÇÃO POR Toxoplasma gondii, Neospora caninum, Leishmania major E Trypanosoma cruzi EM CÃES DO ESTADO DO PARÁ
}

\section{INFECTION BY Toxoplasma gondii, Neospora caninum, Leishmania major AND Trypanosoma cruzi IN DOGS FROM THE STATE OF PARÁ}

\author{
Giselle Souza da Paz ${ }^{1}$ ORCID - http://orcid.org/0000-0002-9845-2501 \\ Bruna da Silva Colhado ${ }^{1}$ ORCID - http://orcid.org/0000-0003-1033-463X \\ Mariane Martinez Anton ${ }^{1}$ ORCID - http://orcid.org/0000-0002-9703-0622 \\ Katarine de Souza Rocha² ORCID - http://orcid.org/0000-0002-9609-3517 \\ Daniela Barbosa da Silva1 ORCID - http://orcid.org/0000-0001-6910-7058 \\ Carla Cristina Guimarães de Moraes² ORCID - http://orcid.org/0000-0001-6702-7660 \\ Simone Baldini Lucheis ${ }^{3}$ ORCID - http://orcid.org/0000-0002-4842-5281 \\ Helio Langoni ${ }^{1^{*}}$ ORCID - http://orcid.org/0000-0001-5127-0762 \\ ${ }^{1}$ Faculdade de Medicina Veterinária e Zootecnia, UNESP, Botucatu, SP, Brasil. \\ ${ }^{2}$ Universidade Federal do Pará, Belém, PA, Brasil. \\ ${ }^{3}$ Agência Paulista de Tecnologia dos Agronegócios (INPA), Bauru, SP, Brasil. \\ *Autor para correspondência - hlangoni@,fmvz.unesp.br
}

\section{Resumo}

Realizou-se inquérito sorológico para Toxoplasma gondii, Neospora caninum, Leishmania spp. e Trypanosoma cruzi em cães dos municípios de Castanhal e Belém, no Estado do Pará, e estudou-se a associação entre os animais sororeagentes e fatores como sexo, idade, acesso a rua e procedência dos animais. Foram utilizados 269 cães de diferentes idades, sadios, provenientes de abrigos de animais, canil comercial, Centro de Controle de Zoonoses e domiciliados. Utilizou-se a reação de imunofluorescência indireta (RIFI), com lâminas sensibilizadas de acordo com os seus respectivos antígenos. Das 263 amostras, 100 foram reagentes, com 38,0\% de positividade para Toxoplasma gondii, sendo os títulos prevalentes $16 \mathrm{UI}$ e $64 \mathrm{UI}, 15,97 \%$ de sororreagentes para anticorpos anti- $N$. caninum com maior soroprevalência para os títulos 25UI e 50UI. Na pesquisa de anticorpos anti- $L$. major, 3,42\% foram sororreagentes com o título 40UI, sendo o mais prevalente. A pesquisa de anticorpos anti-T. cruzi revelou negatividade em todas as amostras. As variáveis procedência e faixa etária mostraram ser um fator de risco para os animais. Os animais de Belém apresentaram 2,6 vezes mais chances de infecção do que os animais de Castanhal. Os animais na faixa etária de três a sete anos apresentaram 2,27 vezes mais chances de serem sororreagentes do que os cães com até três anos de idade. Não houve associação estatística para as demais variáveis e protozoários pesquisados.

Palavras-chave: Toxoplasmose, Leishmaniose, Neosporose, Doença de Chagas, animais domésticos.

\footnotetext{
Abstract

A serological inquiry was performed to Toxoplasma gondii, Neospora caninum, Leishmania spp. and Trypanosoma cruzi in dogs from the city of Castanhal and Belém, State of Pará, and the association between seropositive animals and factors such as sex, age, access to the streets and provenance of the
} 
animals was studied. 269 healthy dogs with different ages, coming from animal shelters, commercial kennels, Zoonosis Control Centre, and domiciles were used. The Indirect immunofluorescence (IIF) reaction was used with plates sensitized with their respective antigens. Among the 263 samples, 100 were reactant, with $38.0 \%$ of positivity for Toxplasma gondii, being 16UI and 64UI the prevalent titers, $15.97 \%$ of reagent animals for anti- $N$. caninum antibodies with higher seroprevalence to titers 25UI and 50UI.At the anti-L. major antibodies research, 3.42\% were reagent with the titer $40 \mathrm{UI}$ being the prevalent. The research of anti-T.cruzi antibodies revealed negativity in all the samples. The provenance and age range variables have been shown as a risk factor to the animals. The animals from the city of Belém presented 2.6 times more changes of infection than the animals from the city of Castanhal. The animals at the age range from three to seven years old presented 2.27 times more changes of being reagent than the dogs with up to three years old. There was no statistical association to the other variables and protozoa researched.

Key-words: Toxoplasmosis, Leishmaniasis, Neosporosis, Chagas disease, Domestic animals.

Recebido em: 13 de janeiro de 2015.

Aceito em: 14 de maio de 2018.

\section{Introdução}

A região amazônica apresenta clima equatorial quente e úmido, apresentando altas temperaturas e umidade relativa do ar em torno de $90 \%$, fatores importantes para a manutenção de diversos protozoários no meio ambiente, expondo animais e humanos ao risco iminente de infecção por estes parasitas.

Toxoplasma gondii é um protozoário, pertencente ao filo Apicomplexa, família Sarcocystidae, agente da toxoplasmose, zoonose de ampla distribuição mundial. Infecta grande variedade de animais domésticos e selvagens, bem como as aves e humanos ${ }^{(1)}$. Inquéritos sorológicos pesquisando $T$. gondii em cães são importantes para se avaliar o grau de dispersão da infecção entre animais e humanos. Os cães podem atuar como sentinelas para avaliação da contaminação ambiental, pois quando a soropositividade na espécie é alta, o ambiente em que ele vive certamente está contaminado por oocistos ou os cães podem está sendo alimentados com carne crua ou mal cozida contendo cistos, e essa carne pode estar servindo de alimento também para os proprietários dos animais ou outras pessoas que convivam com eles ${ }^{(2)}$.

A neosporose acarreta grande impacto econômico na pecuária brasileira, devido a perdas reprodutivas. Protozoário intracelular obrigatório, Neospora caninum pertencente ao Filo Apicomplexa e tem como hospedeiro definitivo os canídeos, que podem eliminar oocistos nas fezes por 8-23 dias após a infecção ${ }^{(3)}$. Bovinos, ovinos, equinos e caprinos são hospedeiros intermediários albergando cistos teciduais em sua musculatura ${ }^{(4)}$. A prevalência em cães, no Brasil, é considerada baixa, com prevalências entre 4,97 e $12,4 \%(5,6,7)$.

A leishmaniose constitui um grande problema de saúde pública no Brasil ${ }^{(8)}$ e os cães são os principais reservatórios da Leishmania infantum chagasi, sendo importantes na cadeia epidemiológica pelo convívio próximo com os humanos. Estes animais por viverem tanto no domicílio como no peridomicílio, são excelentes fontes de repasto sanguíneo para as fêmeas de flebotomíneos em áreas endêmicas. Além disso, a alta densidade populacional, aliada à susceptibilidade dos cães e o grande número de animais assintomáticos são aspectos a serem considerados em saúde pública ${ }^{(9)}$. $\mathrm{O}$ tratamento com medicamentos utilizados no tratamento humano é proibido para a espécie canina. Desta forma, a eutanásia de cães positivos ainda é uma medida preventiva adotada no país, pois 
mesmo com tratamento e menor carga parasitária, os cães tratados permanecem como fontes de infecção por toda vida ${ }^{(10,11)}$.

A Tripanossomíase ou Doença de Chagas é zoonose nativa das Américas, causada pelo Trypanosoma cruzi, afetando humanos, animais selvagens e domésticos. Esta protozoonose assumiu grande importância no Estado do Pará, após a correlação da doença com o consumo do suco de açaí, produto muito apreciado na região ${ }^{(12)}$. O vetor, Triatoma infestans, tem predileção pelo sangue canino, tornando os cães os principais reservatórios domésticos da enfermidade em áreas endêmicas ${ }^{(13)}$, desenvolvendo as fases aguda e crônica, semelhante à infecção humana ${ }^{(14)}$.

Desta forma, o objetivo do presente estudo foi a realização de inquérito sorológico para Toxoplasma gondii, Neospora caninum, Leishmania spp. e Trypanosoma cruzi em cães dos municípios de Castanhal e Belém, no Pará, e verificar a associação entre os animais sororreagentes e fatores como sexo, idade, acesso a rua e procedência dos animais.

\section{Materiais e Métodos}

A pesquisa foi realizada nas cidades de Belém (latitude: $01^{\circ} 27^{\prime} 21^{\prime \prime} \mathrm{S}$ e longitude: $48^{\circ} 30^{\prime} 16^{\prime \prime} \mathrm{W}$ ) e Castanhal (latitude: $01^{\circ} 17^{\prime} 38^{\prime \prime} \mathrm{S}$ e longitude: $47^{\circ} 55^{\prime} 35^{\prime \prime} \mathrm{W}$ ), localizadas na região nordeste do Estado do Pará. Apresentam temperatura média anual de $26^{\circ} \mathrm{C}$, umidade relativa do ar média de $90 \%$, provocando chuvas de 2500 a $3000 \mathrm{~mm}$. As estações são simplesmente divididas entre a época que "chove muito", que vai de dezembro ao início de maio, e a época que "chove menos", de junho a novembro.

Até o presente momento não há censo canino nestes municípios e há poucos dados sobre a população de animais domésticos na região. Segundo divulgado pela Secretária Municipal de Saúde de Belém, foram imunizados 127 mil cães durante a campanha de vacinação antirrábica em 2009. Em Castanhal não foram divulgados dados no mesmo ano.

A pesquisa foi aprovada pelo comitê de ética de Uso Animal (CEUA), da Faculdade de Medicina Veterinária e Zootecnia (FMVZ), UNESP, Botucatu. As amostras foram obtidas entre agosto de 2009 e janeiro de 2010. Não foram adotados critérios probabilísticos para a seleção dos animais, de maneira que as colheitas de sangue foram realizadas por conveniência, adotando-se como critério a autorização do proprietário e a ausência de sintomatologia clínica nos animais. As colheitas de sangue foram realizadas em sete bairros da região metropolitana de Belém e 10 bairros e um distrito de Castanhal, realizando-se visitas de porta em porta nos domicílios. Foram avaliados 263 cães, sendo 129 da cidade de Belém e 134 de Castanhal, provenientes de abrigos de animais (88), canil comercial (16), Centro de Controle de Zoonoses (CCZ) de Belém (31) e de domicílios (128).

Antes da colheita de sangue, foi aplicado questionário aos responsáveis pelos cães, anotando características como: local onde os animais viviam (abrigos de animais, canil comercial, CCZ ou domicílios), sexo, raça e idade dos animais, a saber: cães com até três anos, entre três a sete anos, e cães com mais de sete anos. Quanto ao acesso à rua foram categorizados em animais que ficavam somente em casa ou quintal, cães sem acesso a rua, e animais que tinham acesso frequente às ruas, sem a presença do responsável, e 'às vezes', no caso de cães que tinham acesso à rua somente com a coleira e acompanhados por seu proprietário.

O sangue foi colhido por venopunção jugular ou cefálica, com o auxílio de agulhas estéreis (30 x 8), em tubos a vácuo (Vaccutainer ${ }^{\circledR}$ ) estéreis sem anticoagulante. Após a retração do coágulo, as 
amostras foram centrifugadas por dez minutos a 3000rpm, acondicionadas em microtubos plásticos (Eppendorf ${ }^{\circledR}$ ) e armazenadas em temperatura de $-20{ }^{\circ} \mathrm{C}$ até a realização das provas sorológicas.

Para realização da RIFI, o antígeno de $N$. caninum foi obtido por cultivo celular, utilizando a estirpe NC-1 de Neospora caninum a qual foi cultivada in vitro em células VERO (células de rim de macaco verde africano). Para manutenção dos taquizoítos, estes foram inoculados em frascos estéreis de 25 $\mathrm{cm}^{2}$ contendo monocamada de células VERO e meio RPMI 1640 (LGCbioß) suplementado com soluções de antimicrobianos $10 \%$ (Vitrocell ${ }^{\circledR}$ ) contendo $100 \mathrm{U} / \mathrm{mL}$ de penicilina, $100 \mu \mathrm{g} / \mathrm{mL}$ de estreptomicina e $0,25 \mu \mathrm{g} / \mathrm{mL}$ de anfotericina $\mathrm{B}$, com incubação em estufa a $37^{\circ} \mathrm{C}$, em $5 \%$ de $\mathrm{CO}^{2}$, com umidade controlada.

Os antígenos de L. major e T. cruzi foram obtidos por cultivo em meio líquido LIT (Liver Infusion Tryptose), suplementado com soro fetal bovino e solução de antibiótico (Gentocin ${ }^{\circledR} 40 \mathrm{mg} / \mathrm{mL}$ ) e em meio sólido NNN (McNeall, Novy \& Nicolle) mantidos a $26^{\circ} \mathrm{C}$, com repiques a cada 15 dias.

$\mathrm{O}$ antígeno de $T$. gondii foi obtido a partir de lavado intraperitoneal de camundongos Swiss de 30 dias, previamente inoculados com suspensão de taquizoítos de Toxoplasma gondii, cepa RH. Para realização da técnica, os antígenos são previamente fixados em lâminas e conservados a $-20^{\circ} \mathrm{C}$ por período máximo de 30 dias.

A pesquisa de anticorpos anti-N. caninum, anti-L. major e anti-T. cruzi e anti-T. gondii foram realizadas pela técnica de Reação de Imunofluorescência Indireta ${ }^{(15)}$, no Núcleo de Pesquisa em Zoonoses - NUPEZO, da Faculdade de Medicina Veterinária e Zootecnia, UNESP, Campus de Botucatu, nos anos de 2013 e 2014. O ponto de corte estabelecido para $N$. caninum foi a diluição 1:25 pesquisando-se a presença de anticorpos até 1:400. O ponto de corte para L. major e T. cruzi foi 1:40, pesquisando-se até a diluição 1:640. Para $T$. gondii utilizou-se diluição inicial 1:16 e máxima de $1: 4096$.

As variáveis: cidade, local onde viviam, idade, sexo, raça e acesso à rua foram submetidas à análise univariada frente aos animais reagentes para os protozoários estudados.

Inicialmente foram produzidas distribuições de frequência para as variáveis e o teste de Qui-quadrado (PROC FREQ; SAS Institute, 2011) foi usado para comparar a proporção de animais sororreagentes entre as classes dos possíveis fatores de risco estudados. Posteriormente, utilizou-se um modelo de regressão logística (PROC GLIMMIX; SAS Institute, 2011) para estimar a Razão de chances (Odds Ratio) de um animal ser soropositivo entre as classes dos fatores previamente associados à positividade. Foi adotado o nível de significância de $5 \%(\alpha=0,05)$.

\section{Resultados}

Dos animais avaliados, 38,0\% ( $\mathrm{N}=100)$ foram sororreagentes para anticorpos anti- $T$. gondii, com maior frequência dos títulos 16UI e 64UI. Encontraram-se 16,0\% $(\mathrm{N}=42)$ de animais sororreagentes para anticorpos anti- $N$. caninum com maior soroprevalência para os títulos 25UI e 50UI. Quanto à pesquisa de anticorpos para L. major, 3,4\% $(\mathrm{N}=09)$ dos cães foram reagentes, sendo o título de 40UI o prevalente (Tabela 1). Todos os animais foram negativos na pesquisa de anticorpos anti-T. cruzi.

Coinfecção para $T$. gondii e $N$. caninum foi verificada em 25 cães, três animais apresentaram anticorpos para $T$. gondii e Leishmania major e um animal apresentou coinfecção para $N$. caninum e L. major. Nenhum animal apresentou coinfecção para os três parasitas. 
As variáveis cidade, local, idade e acesso à rua, foram associadas à positividade para toxoplasmose $(\mathrm{P}<0.05$; Tabela 2). Após análise multivariada as variáveis, cidade e faixa etária, permaneceram no modelo final de regressão logística. Verificou-se que as chances de um animal ser soropositivo foram 2,65 vezes maiores para os animais amostrados de Belém, quando comparados aos animais amostrados de Castanhal $(\mathrm{P}<0,01)$. Da mesma forma, as chances de soropositividade foram 2,27 vezes maiores para os animais entre 3 e 7 anos de idade, quando comparados aos animais até três anos de idade $(\mathrm{P}<0,01)$ (Tabela 3$)$.

Na pesquisa de anticorpos anti-N. caninum houve associação estatística para as variáveis cidade, local onde viviam e idade, porém quando submetidos a regressão logística, não houve diferença estatística $(\mathrm{P}<0.05$; Tabela 2). Não houve associação estatística entre os animais reagentes a anticorpos anti- $L$. major e as variáveis estudadas $(\mathrm{P}<0.05$; Tabela 2$)$.

Tabela 1. Percentual de animais sororreagentes para anticorpos anti- $T$. gondii, $N$. caninum e Leishmania major em cães nas cidades de Belém e Castanhal. Botucatu, 2016

\begin{tabular}{|c|c|c|c|c|c|c|}
\hline \multirow[b]{2}{*}{ Protozoários } & \multicolumn{6}{|c|}{ Títulos } \\
\hline & 16 & 64 & 256 & 1024 & 4096 & Total \\
\hline $\begin{array}{c}\text { Toxoplasma } \\
\text { gondii }\end{array}$ & $48(18,2 \%)$ & $35(13,3 \%)$ & $11(4,2 \%)$ & $04(1,5 \%)$ & $02(0,7 \%)$ & $100(38,0 \%)$ \\
\hline $\begin{array}{l}\text { Neospora } \\
\text { canimum }\end{array}$ & $\begin{array}{c}\mathbf{2 5} \\
17(6,5 \%)\end{array}$ & $\begin{array}{c}\mathbf{5 0} \\
17(6,5 \%) \\
\end{array}$ & $\begin{array}{c}100 \\
8(3,0 \%) \\
\end{array}$ & $\begin{array}{c}200 \\
-\end{array}$ & $\begin{array}{c}400 \\
-\end{array}$ & $42(16,0 \%)$ \\
\hline $\begin{array}{l}\text { Leishmania } \\
\text { major }\end{array}$ & $\begin{array}{c}40 \\
6(2,3 \%)\end{array}$ & $\begin{array}{c}\mathbf{8 0} \\
3(1,1 \%)\end{array}$ & 160 & $\begin{array}{c}320 \\
-\end{array}$ & $\begin{array}{c}640 \\
-\end{array}$ & $9(3,4 \%)$ \\
\hline
\end{tabular}

Tabela 2. Avaliação dos fatores de risco para a soropositividade para leishmaniose, neosporose e toxoplasmose em cães nos municípios de Belém e Castanhal. Botucatu, 2016

\begin{tabular}{|c|c|c|c|c|c|c|c|}
\hline \multirow[b]{2}{*}{ Variáveis } & \multirow[b]{2}{*}{ Total } & \multicolumn{2}{|c|}{ Leishmania major } & \multicolumn{2}{|c|}{ Neospora caninum } & \multicolumn{2}{|c|}{ Toxoplasma gondii } \\
\hline & & $\begin{array}{c}\text { Positivos, } \mathbf{~} \\
(\%)\end{array}$ & Valor-P & Positivos, N (\%) & Valor-P & $\begin{array}{c}\text { Positivos, N } \\
(\%)\end{array}$ & Valor-P \\
\hline Cidade & & & 0.77 & & 0.0016 & & 0.0001 \\
\hline Belém & 129 & $4(3.1)$ & & $30(23.44)$ & & $64(49.6)$ & \\
\hline Castanhal & 134 & $5(3.7)$ & & $12(8.7)$ & & $36(26,9)$ & \\
\hline Local & & & 0.38 & & $<0.0001$ & & 0.008 \\
\hline Abrigo & 88 & $5(5.7)$ & & $16(18.2)$ & & $32(36.4)$ & \\
\hline $\mathrm{CCZ}$ & 31 & $0(0.0)$ & & $14(45.2)$ & & $19(61,3)$ & \\
\hline Canil & 16 & $0(0.0)$ & & $0(0.0)$ & & $03(18,7)$ & \\
\hline Domicílio & 128 & $4(3.1)$ & & $12(9.4)$ & & $46(35.9)$ & \\
\hline Sexo & & & 0.91 & & 0.09 & & 0.2 \\
\hline Fêmeas & 171 & $6(3.5)$ & & $32(18.7)$ & & $69(40.3)$ & \\
\hline Machos & 92 & $3(3.3)$ & & $10(10.9)$ & & $31(33.7)$ & \\
\hline Idade (anos) & & & 0.66 & & 0.02 & & 0.004 \\
\hline $0-3$ & 107 & $3(2.8)$ & & $9(8.4)$ & & $29(27.1)$ & \\
\hline $3-7$ & 123 & $4(3.2)$ & & $26(21.1)$ & & $57(46.3)$ & \\
\hline$>7$ & 33 & $2(6.1)$ & & $7(21.2)$ & & $14(42.4)$ & \\
\hline Raça & & & 0.97 & & 0.08 & & 0.6 \\
\hline Pedigree & 54 & $0(0.0)$ & & $4(7.4)$ & & $20(37.0)$ & \\
\hline SRD & 209 & $9(4.3)$ & & $38(18.2)$ & & $80(38.3)$ & \\
\hline Acesso a rua & & & 0.65 & & 0.47 & & 0.03 \\
\hline Às vezes & 31 & $1(3.2)$ & & $6(19.3)$ & & $18(58.1)$ & \\
\hline Nunca & 211 & $8(3.8)$ & & $31(14.7)$ & & $74(35.1)$ & \\
\hline Sempre & 21 & $0(0.0)$ & & $5(23.8)$ & & $08(38.1)$ & \\
\hline
\end{tabular}


Tabela 3. Resultados da análise multivariada dos fatores de risco para infecção por Toxoplasma gondii em cães de Belém e Castanhal, Pa. Botucatu, 2016

\begin{tabular}{cccc}
\hline Variável & Odds Ratio & I.C. 95\% & Valor-P \\
\hline Cidade $^{1}$ & 2.65 & {$[1.57-4.48]$} & 0.0001 \\
Faixa etária $^{2}$ & 2.27 & {$[1.30-4.17]$} & 0.004 \\
\hline
\end{tabular}

'A cidade de Belém em relação a cidade de Castanhal; ${ }^{2}$ Animais de 3 a 7 anos em relação aos cães com 0 a 3 anos.

\section{Discussão}

Os resultados confirmam a dispersão do $T$. gondii no ambiente e a importância dos inquéritos soroepidemiológicos em cães, uma vez que são considerados animais sentinelas para a infecção ${ }^{(2,5,16)}$. A soroprevalência de $37,3 \%$, obtida na presente pesquisa foi inferior a encontrada em outros estudos realizados no Brasil ${ }^{(3,4,17,18,19)}$. Porém, superior a encontrada por Lopes et al. ${ }^{(20)}$ e Langoni et al. ${ }^{(5)}$, em estudo realizado em cães nas cidades de Teresina-PI e Brotas-SP, respectivamente.

A pesquisa de anticorpos anti- $N$. caninum revelou soroprevalência semelhante a outros inquéritos sorológicos realizados no Brasil ${ }^{(7,21,22)}$. O presente estudo é o primeiro a realizar pesquisa de anticorpos anti-N. caninum na região nordeste do Estado do Pará. Valadas et al. ${ }^{(6)}$ realizaram pesquisa de anticorpos anti- $N$. caninum em municípios do sul e do centro-oeste do Estado, e encontraram $12,4 \%$ de cães reagentes, semelhante aos resultados da presente pesquisa. Demonstrando que cães de áreas urbanas da Amazônia também estão expostos a este coccídeo. Estudos avaliando a prevalência de neosporose em cães de áreas rurais no Estado devem ser incentivados, visto que cães positivos são reservatórios do parasita ${ }^{(22)}$ e o Estado do Pará possui o segundo maior rebanho bovino do país e é responsável por mais da metade do rebanho ovino da região Norte.

O cão é o principal reservatório urbano na leishmaniose ${ }^{(23)} \mathrm{e}$ a soroprevalência nos cães das cidades de Belém e Castanhal foi de 3,42\%, sem diferença estatística entre ambas. Resultados semelhantes foram encontrados por Maywald et al. ${ }^{(24)}$ em Uberlância e Coromanel, ambas em Minas Gerais, que detectaram 4,8\% dos cães positivos para anticorpos anti-Leishmania spp. Soroprevalência elevada foi encontrada dentre 322 cães avaliados em estudo realizado por Dantas-Torres et al. ${ }^{(25)} \mathrm{em}$ Pernambuco.

A detecção de anticorpos circulantes em amostras de cães das duas cidades, apesar da baixa soroprevalência revela a presença do parasita na região estudada. Corroborando com outros estudos realizados no Estado que também detectaram cães reagentes para anticorpos anti-Leishmania spp. ${ }^{(6,26,27)}$. É importante o desenvolvimento de novas pesquisas na região, pois o agente etiológico, o vetor e o principal reservatório urbano (cão) do parasita estão presentes no ambiente que é propício tanto para a manutenção do agente como do vetor.

No presente estudo não foram diagnosticados cães reagentes para anticorpos anti-T. cruzi. Semelhante a Maywald et al. ${ }^{(24)}$ que avaliaram 230 cães em dois municípios de Minas Gerais e também não detectaram nenhum animal reagente para anticorpos anti-T. cruzi pela reação de Imunofluorescência Indireta. No entanto, estudos demonstraram elevada prevalência em cães do Mato Grosso do Sul ${ }^{(28)}$. Apesar do resultado sorológico negativo para anticorpos anti-T. cruzi do presente estudo, há o relato de cão positivo para Doença de Chagas, com manifestação clínica no município de Castanhal ${ }^{(29)}$. No município de Abaetetuba-PA, foi diagnosticado o parasita em animais silvestres e domésticos, incluindo o cão ${ }^{(30)}$. Ressalta-se que este é o primeiro estudo sorológico pesquisando anticorpos antiT. cruzi em cães no Estado e sugere-se a realização de novos estudos, incluindo regiões distintas do 
Estado.

Após análise estatística, a variável cidade foi considerada um fator de risco para a infecção por $T$. gondii, e os cães da cidade de Belém apresentaram 2,6 vezes mais chances de serem sororreagentes a anticorpos anti- $T$. gondii do que os animais de Castanhal. Isso pode ser justificado pelas características climáticas da cidade de Belém, que comparada a Castanhal, tem um clima mais úmido pela maior precipitação pluviométrica, o que aliado à elevada temperatura e a presença de $\mathrm{O}_{2}$ favorece a esporulação do oocisto, tornando-o infectante, contribuindo para a disseminação da infecção.

Quanto à ocorrência de anticorpos contra- $N$. caninum, Belém apresentou maior número de animais reagentes, porém não houve diferença estatística entre os dois municípios. Ressalta-se que a infecção pelo protozoário pode ocorrer por transmissão vertical (transplacentária) não necessitando, portanto, de um hospedeiro intermediário para completar o ciclo biológico ${ }^{(3)}$, o que justificaria a ocorrência de cães sororreagentes no ambiente urbano, e a elevada prevalência em Belém.

Os cães que viviam no Centro de Controle de Zoonoses de Belém apresentaram maior número de animais reagentes para $T$. gondii e $N$. caninum, seguido dos mantidos em abrigos, corroborando com Teixeira et al. ${ }^{(31)}$ que também encontraram elevada frequência de animais sororreagentes para $N$. caninum dentre cães capturados pelo Centro de Controle de zoonoses de São Luís-MA. A aglomeração de cães de diferentes bairros da cidade pode favorecer a transmissão entre eles. Esses animais por dividirem os mesmos espaços, consequentemente entram em contato com as fezes uns dos outros, e se houver um animal infectado, eliminando oocistos, em consequência ocorre a disseminação da infecção. Cães que viviam em ambiente doméstico apresentaram menor taxa de soroprevalência, e animais de canis comerciais foram sorologicamente negativos para $N$. caninum e apresentaram baixa soroprevalência de anticorpos anti- $T$. gondii. Talvez o pouco ou nenhum contato com outros cães, justifique a diferença dos resultados de soroprevalência entres os grupos, e o fato desses animais serem alimentados apenas com ração industrializada e raramente terem acesso ao ambiente rural.

Após análise estatística os cães na faixa etária entre três a sete anos revelaram 2,27 vezes mais chances de apresentarem anticorpos anti- $T$. gondii quando comparados com os animais de até três anos de idade. Cães com idade superior a três anos também apresentaram maior frequência de infecção para N. caninum e os com idade superior a sete anos apresentaram maior soroprevalência para anticorpos anti-Leishmania spp., entretanto sem associação estatística para os dois parasitas, corroborando com outras pesquisas descritas na literatura ${ }^{(5,7,17,18,32)}$. As chances de infecção aumentam com o passar da idade pelas maiores chances de exposição ao agente ${ }^{(33)}$.

Não houve associação estatística para as variáveis acesso à rua, sexo e raça, para nenhum dos protozoários pesquisados. Semelhante aos resultados de Cañón-Franco et al. ${ }^{(7)}$, Teixeira et al. ${ }^{(31)}$ e Valadas et al. ${ }^{(6)}$, sugerindo que machos e fêmeas são igualmente susceptíveis.

Quanto o acesso à rua, Fridlund-Plugge et al. ${ }^{(22)}$ também não observaram diferença estatística entre cães domiciliados e cães de rua. Azevedo et al. ${ }^{(21)}$ concluíram que animais com acesso à rua foram mais predispostos à infecção por $N$. caninum, quando comparados aos que viviam exclusivamente em ambiente doméstico. Teoricamente, animais que vivem em ambientes isolados como o domicílio humano, consequentemente entram em contato com um menor número de patógenos e apresentam menos risco de infecção. 


\section{Conclusão}

A infecção por T. gondii e N. caninum ocorre em cães nas cidades de Belém-PA e Castanhal-PA, e, considerando-se que estes animais são sentinelas para a infecção pelo $T$. gondii, há que se considerar que há fatores de riscos de infecção para a população humana local. Os cães do município de Belém na faixa etária entre três e sete anos apresentaram mais chances de serem sororreagentes a anticorpos anti-T. gondii quando comparados com animais de Castanhal e com cães com idade até três anos.

Apesar da baixa frequência de cães sororreagentes para anticorpos anti-Leishmania spp., ressalta-se a presença do mosquito transmissor na região, desta forma, medidas preventivas não devem ser negligenciadas, visto que os cães são os principais reservatórios urbanos do parasita. Não se encontrou animais positivos para Trypanosoma cruzi, entretanto novos estudos devem ser realizados para se elucidar melhor o papel do cão nesta região que é considerada endêmica para Doença de Chagas.

\section{Referências}

1. Fialho CG, Teixeira MC, Araujo FAP. Toxoplasmose animal no Brasil. Acta sci. vet. 2009; 37(1): 1-23.

2. Salb AL, Barkema HW, Elkin BT, Thompson RCA, Whiteside DP, Black SR, et al. Dogs as sources and sentinels of parasites in human and wildlife, Northern Canadá. Emerg Infect Dis. 2008; 14(1):60-63.

3. Dubey JP, Schares G, Ortega-Mora LM. Epidemiology and control of neosporosis and Neospora caninum. Clin. Microbiol. Rev. 2007; 20(2): 323-367.

4. Dubey JP, Lindsay DS. A review of Neospora caninum and neosporosis. Veterinary Parasitology. 1996; 67(1-2): 1-59.

5. Langoni H, Fornazari F, Silva RC, Monti ET, Villa FB. Prevalence of antibody es against Toxoplasma gondii and Neospora caninum in dogs. Brazilian Journal of Microbiology. 2013; 44(4): 1327-1330.

6. Valadas S, Minervino AHH, Lima VMF, Soares RM, Ortolani EL, Gennari SM. Occurrence of antibodies anti-Neospora caninum, anti-Toxoplasma gondii, and anti-Leishmania chagasi in serum of dogs from Pará State, Amazon. Brazilian Parasitology Research. 2010; 107: 453-457.

7. Cañón-Franco WA, Bergamaschi DP, Labruna MB, Camargo LMA, Souza SLP, Silva JCR, Pinter A, Dubey JP, Gennari SM. Prevalence of antibodies to Neospora caninum in dogs from Amazon, Brazil. Veterinary Parasitology. 2003; 115(1): 71-74.

8. Silveira FT, Shaw JJ, Bichara CNC, Costa JM. Leishmaniose visceral americana. In: Doenças Infecciosas e Parasitárias: Enfoque Amazônico/ Raimundo Nonato Queiroz de Leão (coordenador), Belém: Cejup: UEPA: Instituto Evandro Chagas; 1997. 619-630.

9. Killick-Kendrick R, Killick-Kendrick M, Foucheaux C, Delure J, Puech MP, Cadiergues MC. Controle da Leishmaniose canina - proteção de cães contra picadas de mosquitos do gênero flebótomos com coleiras de deltametrina. Medical and Veterinary Entomology. 1997; 11(2): 105-111.

10. Donato LE, Lima Júnior, FEF, Albuquerque R, Gomes MLS. Vigilância e Controle de reservatórios da Leishmaniose Visceral no Brasil: aspectos técnicos e jurídicos. Revista de Educação Continuada em Medicina Veterinária e Zootecnia do CRMV-SP. 2013; 11 (2): 18-23.

11. Costa CHN, Vieira JBF. Mudanças no controle da leishmaniose visceral no Brasil. Informe Técnico. Rev 
Socied Bras Med Trop. 2001; 34(2): 223-228.

12. Valente SAS, Valente VC, Fraiha Neto H. Considerations on the epidemiology and transmission of Chagas disease in the Brazilian Amazon. Memórias do Instituto Oswaldo Cruz. 1999; 94: 395-8.

13. Gurtler RE, Cecere MC, Castanera MB, Canale D, Lauricella MA, Chuit R, et al. Probability of infection with Trypanosoma cruzi of the vector Triatoma infestans fed on infected humans and dogs in northwest Argentina. Am J Trop Med Hvg. 1996; 55 (1): 24-31.

14. Esch KJ, Petersen CA. Transmission and Epidemiology of Zoonotic Protozoal Diseases of Companion Animals. Clin Microbiol Rev. 2013; 26(1): 58-85.

15. Camargo, ME. Introdução as técnicas de imunofluorescência. Rev Bras Patol Clín. 1974; 10(3): 87-107.

16. Ullmann LS, Guimarães FF, Fornazari F, Tomé RO, Camossi LG, Greca H, et al. Ações de vigilância continuada, papel do cão como animal sentinela para toxoplasmose. Revista Brasileira de Parasitologia Veterinária. 2008; 17(1): 345-347.

17. Garcia JI, Navarro IT, Ogawa L, Oliveira RC. Soroepidemiologia da toxoplasmose em gatos e cães de propriedades rurais do município de Jaguapitã, Estado do Paraná, Brasil. Ciência rural.1999; 29(1): 99-104.

18. Minervino AHH, Cassinelli ABM, Lima JTR, Soares HS, Malheiros AF, Marcili A, et al. Prevalence of anti-Neospora caninum and anti-Toxoplasma gondii antibodies in dogs from two different indigenous communities in the Brazilian Amazon region. Journal of Parasitology. 2012; 98(6): 1276-1278.

19. Paz GS, Silva AL, Paiz LM, João CF, Langoni H. Pesquisa de anticorpos anti-Toxoplasma gondii e antiLeishmania ssp. em cães de Castanhal, Pará. In: Congresso Brasileiro de Parasitologia, 23, 2013, Florianópolis. Anais... Florianópolis: XXIII Congresso Brasileiro de Parasitologia, 2013.

20. Lopes MG, Mendonça IL, Fortes KP, Amaku M, Pena HFJ, Gennari SM. Presence of antibodies against Toxoplasma gondii, Neospora caninum and Leishmania infantum in dogs from Piauí. Revista Brasileira de Parasitologia Veterinária. 2011; 20(2): 111-114.

21. Azevedo SS, Batista CSA, Vasconcellos AS, Aguiar DM, Ragozo AMA, Rodrigues AAR, et al. Seroepidemiology of Toxoplasma gondii and Neospora caninum in dogs from the state of Paraíba, Northeast region of Brazil. Research in Veterinary Science. 2005; 79(1): 51-56.

22. Fridlund-Plugge N, Montiani-Ferreira F, Richartz RRTB, Pizzol JD, Machado Junior PC, Patrício LFL, et al. Frequency of antibodies against Neospora caninum in stray and domiciled dogs from urban, periurban and rural areas from Paraná State, Southern Brazil. Rev Bras Parasitol Vet (Online). 2008 Out/Dez [Cited 2014 $\begin{array}{llllll}\text { November } & 14]\end{array}$ (4): 222-226. $17 \quad$ Available from: http://www.scielo.br/scielo.php?script=sci arttext\&pid=S1984$29612008000400010 \& \operatorname{lng}=\mathrm{pt \& nrm}=$ is\&tlng=en.

23. Brasil. Ministério da Saúde. Secretaria de Vigilância em Saúde. Departamento de Vigilância Epidemiológica. Manual de Vigilância e Controle da Leishmaniose Visceral. Série A. Normas e Manuais Técnicos. $1^{\text {a }}$ Ed. Brasilia, DF, 2006.

24. Maywald PG, Machado MI, Costa-Cruz JM, Gonçalves-Pires MRF. Leishmaniose tegumentar, visceral e doença de Chagas caninas em municípios do Triângulo Mineiro e Alto Paranaíba, Minas Gerais, Brasil. Cadernos de Saúde Pública. 1996; 12(3): 321-328.

25. Dantas-Torres F, Brito MEF, Brandão-Filho SP. Seroepidemiological survey on canine leishmaniasis among dogs from an urban area of Brazil. Veterinary Parasitology. 2006; 140(1-2): 54-60.

26. Schwanke K, Silva AMM, Pacheco A, Bahia M, Silveira FT, Scofield A, Góes-Cavalcante G. Diagnóstico molecular e freqüência de anticorpos anti-Leishmania infantum chagasi em cães do município de Belém, Pará. 
Pesquisa Veterinária Brasileira. 2014; 34(3): 255-260.

27. Figueiredo FMM, Souza NF, Figueiredo HF, Meneses AMC, Silva Filho E, Nascimento GG. Fatores de risco e classificação clínica associados à soropositividade para Leishmaniose Visceral Canina. Ciência Animal Brasileira. 2014; 5(1): 102-106.

28. Souza AI. Estudo clínico da infecção natural por T. cruzi em cães residentes em uma área rural de Mato Grosso do Sul, Brasil [Tese]. Jaboticabal: Universidade Estadual Paulista; De 2007. Available from: http://base.repositorio.unesp.br/handle/11449/101268.

29. Araújo IM, Domiciano TAO, Jorge EM, Paredes LJA, Machado FMC, Bezerra Júnior OS. Infecção por Trypanosoma cruzi em um cão domiciliado da área urbana do Município de Castanhal, Estado do Pará, Brasil. ARS Veterinária. 2013; 29 (4): 56.

30. Roque ALR, Xavier SCC, Gerhardt M, Silva MFO, Lima VS, D'andrea OS, et al. Trypanosoma cruzi among wild and domestic mammals in different areas of the Abaetetuba municipality (Pará State, Brazil), an endemic Chagas disease transmission area. Veterinary Parasitology. 2013; 193 (1-3): 71-77.

31. Teixeira WC, Silva MIS, Pereira JG, Pinheiro AM, Almeida MAO, Gondim LFP. Freqüência de cães reagentes para Neospora caninum em São Luís, Maranhão. Arquivo Brasileiro de Medicina Veterinária e Zootecnia. 2006; 58 (4): 685-687.

32. Wouda W, Dijkstra T, Kramer AMH, Maanen C, Brinkhof JMA. Seroepidemiological evidence for a relationship between Neospora caninum infections in dogs and cattle. International Journal for Parasitology. 1999; 29: 1677-1682.

33. Bresciani KDS, Costa AJ, Navarro IT, Toniollo GH, Sakamoto CAM, Arantes TP, et al. Toxoplasmose canina: Aspectos clínicos e patológicos. Semina: ciências agrárias. 2008; 29(1): 189-202. 